\title{
Treatment of Graves' disease with methimazole in children alters the proliferation of Treg cells and CD3 + T lymphocytes
}

\author{
Maria Klatka ${ }^{1}$, Lucyna Kaszubowska ${ }^{2}$, Ewelina Grywalska ${ }^{3}$, Magdalena Wasiak ${ }^{4}$, \\ Leszek Szewczyk ${ }^{1}$, Jerzy Foerster ${ }^{5}$, Marta Cyman², Jacek Rolinski ${ }^{3}$
}

${ }^{1}$ Department of Pediatric Endocrinology and Diabetology, Medical University of Lublin, Lublin, Poland

${ }^{2}$ Department of Histology, Medical University of Gdansk, Gdansk, Poland

${ }^{3}$ Department of Clinical Immunology and Immunotherapy, Medical University of Lublin, Lublin, Poland

${ }^{4}$ Department of Otolaryngology and Laryngeal Oncology, Medical University of Lublin, Lublin, Poland

${ }^{5}$ Department of Social and Clinical Gerontology, Medical University of Gdansk, Gdansk, Poland

\begin{abstract}
Almost all cases of hyperthyroidism in children result from Graves' disease (GD). Recent studies have confirmed a significant role of T regulatory cells (Tregs) in the development of autoimmune diseases. However, the interactions between $T$ cell responses and Treg proliferation in GD are still poorly understood. The aim of this study was to assess the proliferation of Treg cells (Tregs) and CD3 + T lymphocytes isolated from 50 children with GD before and after treatment with the thyreostatic drug methimazole (MMI). The proliferation rates, measured by methyl-3H-thymidyne incorporation, of CD3+ cells and Tregs stimulated with mitogen phorbol 12-myristate 13-acetate (PMA) were compared with those of unstimulated cells. The proliferation rates of both PMA-stimulated and unstimulated CD3 + cells prior to treatment with MMI were significantly higher than after treatment. Simultaneously, the proliferation rates of both PMA-stimulated and unstimulated Tregs were significantly lower before MMI treatment. Moreover, we observed higher cell proliferation rates of unstimulated and PMA-stimulated Tregs before the initiation of MMI therapy and after treatment in patients who had no relapse of hyperthyroidism. There was a positive correlation between the $\mathrm{CD} 3+$ cells proliferation rate before MMI treatment and fT3, as well as fT4 concentration in peripheral blood. The proliferation rates of CD3+ T cells before and after MMI treatment positively correlated with the TSI index. Thus, children suffering from Graves' disease presented lower Tregs proliferative potential compared with CD3+ T cells. Cocultures of CD3+ $T$ cells and Tregs showed that Tregs were not capable of efficiently inhibiting the proliferation of CD3+ T cells in GD patients. Conclusions. MMI treatment reduced the proliferative activity of CD3+ T cells in pediatric GD patients and increased the proliferation rate of Tregs. We suggest that Treg cells that are partly dysfunctional in GD disease are probably suppressed by $\mathrm{CD} 3+\mathrm{T}$ cells and that methimazole exerts some immunomodulatory effects. (Folia Histochemica et Cytobiologica 2014, Vol. 52, No. 1, 69-77)
\end{abstract}

Key words: children; Graves' disease; lymphocyte proliferation; methimazole; T cells; Treg cells; PMA

Correspondence address: M. Klatka, M.D., Ph.D.,

Department of Pediatric Endocrinology and Diabetology,

Medical University of Lublin, Chodzki St. 2,

20-093 Lublin, Poland;

tel.: +48 8175648 56, fax: +48 8175648 40;

e-mail: mariaklatka@wp.pl

\section{Introduction}

Hyperthyroidism affects over $2 \%$ of the population, and is $5-10$ times more common in women than in men [1]. Hyperthyroidism in children and adolescents 
has unique effects on growth and development, in addition to causing many of the same symptoms as in adults. Graves' disease (GD) occurs in approximately 0.02 percent of children ( 1 in 5000) and is almost always the cause of hyperthyroidism in this age group [2].

Recent investigations have confirmed the crucial role of $\mathrm{T}$ regulatory cells (Tregs) in the development of autoaggressive diseases, including autoimmune thyroid disease (AITD) [3]. Treg cells are a subset of CD4+ T cells that express high levels of the CD25 molecule and transcription factor forkhead box P3 (FOXP3). Treg cells make up 5-10\% of peripheral CD4+ T cells [4] and can be divided into two subpopulations: the first subpopulation comprises naturally occurring nTreg cells (which emerge de novo from the embryonic/neonatal thymus and are also described as "thymic" Tregs or tTregs), whereasthe second one consists of inducible iTreg cells (induced in the periphery, and also described as "peripheral" Tregs or pTregs), whose function is to acquire a regulatory phenotype in response to pathogens and inflammation [5]. Treg cells exert a key homeostatic effect on two subpopulations of T helper (Th) cells, Th1 and Th2. Th1 cells secrete IFN $\gamma$, IL-2, and IL-12 and are associated with cell-mediated immune responses, while Th2 cells secrete IL-4, IL-5, and IL-10 and are involved in humoral immunity. The imbalance between Th1 and Th 2 cells caused by Treg cell dysfunction may determine the outcome of autoimmune diseases [4].

Treg cells function via negative costimulatory molecules, induction of anti-inflammatory signal transduction pathways in $\mathrm{T}$ cells and antigen-presenting cells, direct or indirect destruction of effector cells or antigen-presenting cells, and secretion of suppressive cytokines [6]. Tregs are involved in the maintenance of immunological self-tolerance through active suppression of self-reactive lymphocytes, and are considered an essential element in the suppression of autoimmune disorders. Defects in their function may result in chronic autoimmunity [7-11]. The impaired function of Treg cells in patients with Graves' disease has also been reported [4]. Moreover, depletion of CD4+CD25+ T cells enhances the development of Graves' hyperthyroidism in the mouse model [12].

Pathogenesis of autoimmune thyroid disease results from a loss of immune tolerance to thyroid antigens [3]. T cells are present in the immune repertoire of patients with GD, and react with appropriately processed peptides derived from all thyroid autoantigens. These autoreactive $\mathrm{T}$ cells in turn stimulate $\mathrm{B}$ cells to produce thyroid-specific autoantibodies, which play a major role in the pathogenesis of var- ious autoimmune diseases. In Graves' disease, TSH receptor antibodies bind to receptors on the surface of follicular cells of the thyroid gland, activate them, and initiate thyroid hormone production that is not under the hypothalamic-hypophyseal control and results in hyperthyroidism. The thyroid-specific autoantibodies are the major targets of immunomodulatory strategies aimed at preventing or delaying the autoimmune onset of thyroid diseases [13]. The thyroid-specific T cells in GD primarily act as helper (CD4+ Th1) $\mathrm{T}$ cells [14]. When activated, these lymphocytes secrete interleukin-2 (IL-2), interferon $\gamma$, and tumor necrosis factor (TNF), which activate cytotoxic (CD8+) $\mathrm{T}$ cells. The Th2 lymphocytes secrete IL-4 and IL-5 and activate antithyroid antibody production. The CD4+ Treg lymphocytes are anti-inflammatory $\mathrm{T}$ cells, which act to diminish the activity of Th1 and Th2 cells [15]. Moreover, the Th1 and Th2 types of $\mathrm{T}$ helper cells interact with each other, so that a predominance of Th1 cells does not necessarily mean that the predominant result is apoptosis [16]. The T cell receptor (TCR) recognizes antigens bound to major histocompatibility complex (MHC) molecules (in humans called also human leukocyte antigens, HLA). This means that the $T$ cell receptor complexes with the HLA molecule on the surface of an antigen-presenting cell: CD8+ cells with HLA class I molecules and CD4+ cells with HLA class II molecules. This complex forms only when the appropriate antigenic peptide is present in the binding pocket of the HLA molecule. Once this complex has been formed, the $\mathrm{T}$ cell requires an additional stimulus to proliferate. This additional stimulus is provided by the same $\mathrm{T}$ cell and the antigen-presenting cells. If no costimulation occurs, the T cell may become anergic. Thyroid cells in autoimmune thyroid disease may express both major histocompatibility complex (MHC) molecules and costimulatory molecules, which aid in intrathyroidal $\mathrm{T}$ cell proliferation [17].

The presence of alloreactive and autoreactive clones in the $\mathrm{T}$ cell repertoire is determined by thymus-dependent pathways, but the activation and expansion of naive clonal populations are regulated in the peripheral lymphoid organs by antigen encounter, homeostatic mechanisms, and the inhibitory network of Treg cells $[18,19]$. However, the interaction between $\mathrm{T}$ cell response and Treg proliferation in GD is still poorly understood.

Methimazole (MMI) is used as a first-line antithyroid drug in children and adolescents with GD [20]. Although it lowers the level of thyroid autoantibodies-sometimes leading to long-term remission [4, $21,22]$ - little is known as yet about its influence on human cell-mediated immune response. 
The aim of our study was to assess in vitro the effects of Treg cells on the proliferation of CD3+ $\mathrm{T}$ lymphocytes in various cocultures of cells isolated from the peripheral blood of children with hyperthyreosis arising from Graves' disease, and to describe the impact of MMI treatment on the proliferation of those cells.

\section{Material and methods}

Study group. The study group consisted of 50 previously untreated adolescent female patients with hyperthyroidism from Graves' disease (mean age 13.42 \pm 1.94; median 13.5; min-max 11-17.2 years), hospitalized at the Department of Pediatrics, Division of Pediatric Endocrinology and Diabetology, Medical University of Lublin, Poland. The patients were diagnosed on the basis of clinical examination and morphological and immunological criteria. In the group of examined children, each presented a wide variety of clinical manifestations of hyperthyroidism at the time of diagnosis. Before beginning antithyroid treatment, blood samples were collected from each child for lymphocyte proliferation assays, and thyroid-stimulating hormone (TSH), free thyroxine (fT4), and free triiodothyronine (fT3) hormone levels were measured. Thyrotropin receptor (TSHR)-stimulating immunoglobulin (TSI index) and the volume of the thyroid gland were also assessed.

The patients were treated with MMI at initial doses of $0.51 \pm 0.05 \mathrm{mg} / \mathrm{kg}$ body weight/day for approximately 4-6 weeks and, after euthyroidism was achieved, blood samples were collected again to measure lymphocyte proliferation and serum hormone levels. Later, the patients received maintenance doses of MMI of approximately $0.1-0.2 \mathrm{mg} / \mathrm{kg}$ body weight/day in combination with a low dose of L-thyroxin, and were observed for 36 months.

None of the children had signs of infection at the time of investigation or for a month before sampling, and none had been taking drugs of known influence on the immune system. None of the patients had undergone blood transfusion. Individuals with a history of allergic diseases were excluded from the study. The research protocol was approved by the Ethics Committee of the Medical University of Lublin and written informed consent was obtained from caretakers or guardians on the behalf of the child participants involved in the study.

Peripheral blood mononuclear cell isolation. Mononuclear cells were isolated from heparinized peripheral blood samples by density gradient centrifugation on Gradisol-L (Aqua Medica, Warsaw, Poland). Interphase cells were collected, washed twice in phosphate-buffered saline (PBS), and cell density was adjusted to $0.5-1 \times 10^{6}$ cells $/ \mathrm{mL}$.

Magnetic separation of CD3 + $\mathrm{T}$ lymphocytes and $\mathrm{T}$ regulatory cells. The separation of $\mathrm{CD} 3+\mathrm{T}$ lymphocytes was conducted using MACS Human CD3 MicroBeads Isolation
Kit (Miltenyi Biotec, Bergisch Gladbach, Germany), while the separation of $\mathrm{CD} 4+\mathrm{CD} 25+$ cells was carried out with a CD4+CD25+ Regulatory T Cell Isolation Kit from the same manufacturer using Vario MACS Separator (Miltenyi Biotec). Mononuclear cells suspended in PBS without $\mathrm{Ca}^{2+}$ and $\mathrm{Mg}^{2+}$ ions were centrifuged and suspended in $1 \mathrm{~mL}$ of a buffer solution (PBS without $\mathrm{Ca}^{2+}$ and $\mathrm{Mg}^{2+}$ ions supplemented with $0.5 \%$ BSA and $2 \mathrm{mM}$ EDTA). Then anti-CD3 antibodies bound to microbeads $\left(20 \mu \mathrm{l} / 10^{7}\right.$ cells $)$ were added and incubated at $4^{\circ} \mathrm{C}$ for $15 \mathrm{~min}$ to isolate $\mathrm{CD} 3+\mathrm{T}$ lymphocytes. Isolation of the $\mathrm{T}$ regulatory cells was conducted in a similar manner following the manufacturer's instructions. After the designated time of incubation, cells were washed with a buffer solution to eliminate unbound antibodies. A column containing a permeable steel matrix was placed in a magnetic field and washed with a cold buffer. Cells were then centrifuged for $10 \mathrm{~min}$ at $300 \mathrm{~g}$, suspended in $10 \mathrm{~mL}$ of buffer and applied to the column. The magnetically bound cells, which constituted a positive fraction, were retained in the column while the unbound population passed through it and constituted a negative fraction. The column was washed twice with cooled buffer. After removing the column from the magnetic field, the bound cells were retrieved by squeezing into a separate test tube. The positive fraction contained CD3 + T lymphocytes and T regulatory cells. Cells were suspended in $1 \mathrm{~mL}$ of PBS, counted, and their viability assessed. The purity of the obtained CD3 + T lymphocyte and $\mathrm{T}$ regulatory cell suspensions was evaluated by flow cytometry (FACS Calibur, Becton Dickinson, San Jose, CA, USA) using relevant monoclonal antibodies coupled with fluorochromes (BD Biosciences Pharmingen, San Jose, CA, USA).

Assessment of the effect of $\mathrm{T}$ regulatory cells on the proliferation of CD3 + T lymphocytes. The assessment of the in vitro proliferation of $\mathrm{CD} 3+\mathrm{T}$ lymphocytes was conducted using a thymidine incorporation assay. Tritiated thymidine (methyl- ${ }^{3} \mathrm{H}$-Thymidine, Perkin Elmer, Waltham, MA, USA) was incorporated into DNA during the $\mathrm{S}$ phase of the cell cycle. The amount of thymidine incorporated into DNA depends on the number of proliferating cells. In order to determine the influence of $\mathrm{T}$ regulatory cells on the proliferation of $\mathrm{CD} 3+\mathrm{T}$ lymphocytes, 72-hour cultures were set up (temperature $37^{\circ} \mathrm{C}, 5 \% \mathrm{CO}_{2}$ ), in which the cells were separated into particular chambers $\left(5 \times 10^{5}\right.$ cells per well $)$ in the following combinations: (i) $\mathrm{CD} 3+$ cells, (ii) $\mathrm{CD} 3+$ cells stimulated with PMA (50 ng/mL), (iii) Treg cells, (iv) Treg cells stimulated with PMA and (v and vi) cocultures of $\mathrm{CD} 3+$ cells and Treg cells stimulated with PMA maintained in ratios 1:2, 1:1 and 2:1 respectively. After 48 hours, $1 \mu \mathrm{Ci}$ of thymidine was added to each chamber. Cells were then cultivated under the same conditions for the subsequent 24 hours. At the end, cells were washed to remove free ${ }^{3} \mathrm{H}$-thymidine and the proliferation rate was measured with 

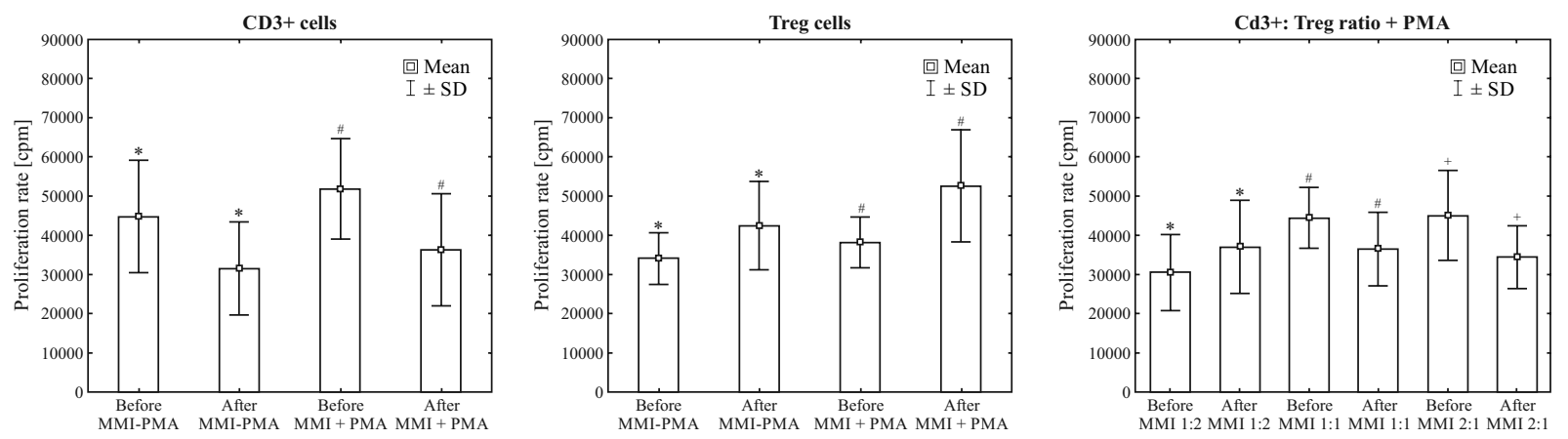

Figure 1. Proliferation rates of CD3 + cells, Treg cells, and cocultures of CD3 + cells and Treg cells unstimulated (- PMA) or stimulated with PMA (+ PMA), before and after MMI treatment. A. Proliferation rates of CD3+ cells unstimulated or stimulated with PMA before or after MMI treatment ( $\left.{ }^{*} \mathrm{p}<0.0001 ;{ }^{*} \mathrm{p}<0.0001\right)$. B. Proliferation rates of Treg cells unstimulated or stimulated with PMA before or after MMI treatment (" $\mathrm{p}<0.0001$; $\left.{ }^{*} \mathrm{p}<0.0001\right)$. C. Proliferation rates of cocultures of CD3 + cells and Treg cells maintained in the ratios: 1:2; 1:1, and 2:1 and stimulated with PMA before and after MMI treatment. The same significance symbols refer to the indicated pair of samples: "before and after MMI treatment, $\mathrm{p}<0.0001$; ${ }^{*}$ before and after MMI treatment, $\mathrm{p}<0.0001$; ${ }^{+}$before and after MMI treatment, $\mathrm{p}<0.0001$

the use of a Micro Beta ${ }^{2}$ LumiJET luminescence counter (Perkin Elmer). The obtained results are presented as averages calculated from three independent measurements.

Statistical analysis. Statistical analysis of the results was conducted using Statistica 9.0 software. The normality of the distribution was evaluated by the Kolmogorov-Smirnov test. Differences between groups were assessed using the Mann -Whitney U test. Pearson or Spearman correlation analyses were performed to estimate the relationships between the variables. Differences with $\mathrm{p}<0.05$ were considered statistically significant.

\section{Results}

\section{Patients' characteristics}

Selected clinical parameters, including fT3 and fT4 concentrations in peripheral blood before and after methimazole treatment, TSI index, and thyroid gland volume before methimazole treatment, are presented in Table 1. From the 50 children included in the study, hyperthyroidism relapse was observed in 18 patients over the 3-year period, despite appropriate treatment. The average elapsed time between achieving euthyreosis and relapse was 21.5 months $( \pm 8.9)$ with a range of between 6 and 35 months.

\section{Lymphocyte proliferation rates before and after treatment with methimazole}

The results of proliferation assays performed in different $\mathrm{T}$ cell culture combinations before the MMI treatment and after MMI-induced euthyreosis are presented in Figure 1. The proliferation rates of CD3 + cells and CD3 + cells stimulated with PMA before MMI treatment were significantly higher than after the treatment $(\mathrm{p}<0.0001)$ (Figure 1A). The proliferation rates of Treg cells and Treg cells stimulated with PMA were significantly lower before the MMI treatment $(\mathrm{p}<0.0001)$ (Figure 1B). Interestingly, before MMI treatment patients suffering from Graves' disease showed higher proliferation rates of CD3 + cells, both PMA-stimulated and unstimulated, compared to the Treg cells.

After treatment with MMI, proliferation rates changed and the patients presented higher proliferation rates of Treg cells, both PMA-stimulated and unstimulated, and decreased proliferation rates of CD3 + cells (Figure 1A, B). The combination of CD3 + cells and Treg cells maintained in the ratio of 1:2 stimulated with PMA resulted in proliferation rates similar to Treg cells (significantly lower than before the MMI treatment). On the contrary, combinations of $\mathrm{CD} 3$ + cells and Treg cells in ratios of $2: 1$ or $1: 1$ stimulated with PMA resulted in proliferation rates similar to those of CD3 + cells (significantly higher than before the MMI treatment; $\mathrm{p}<0.0001)$. These results indicate that Treg cells cocultured in excess with CD3 + cells (CD3+: Treg ratio 1:2) were capable of decreasing the proliferation rate of $\mathrm{CD} 3+$ cells before the treatment with MMI. On the other hand, methimazole reduced the proliferative activity of CD3 + lymphocytes in cocultures with Treg cells maintained in the ratio 1:1 and 2:1 (Figure 1C). 
Table 1. Selected clinical and biochemical parameters analyzed in patients before and after methimazole (MMI) treatment, presented as means $\pm \mathrm{SD}$

\begin{tabular}{|l|c|c|}
\hline Tested parameter & $\begin{array}{c}\text { Before } \\
\text { MMI treatment }\end{array}$ & $\begin{array}{c}\text { After } \\
\text { MMI treatment }\end{array}$ \\
\hline fT3 [pmol/L] & $12.53 \pm 3.91$ & $5.91 \pm 1.21$ \\
\hline fT4 [pmol/L] & $35.31 \pm 13.73$ & $16.82 \pm 2.62$ \\
\hline TSI index & $7.74 \pm 4.72$ & - \\
\hline Thyroid gland volume $[\mathrm{mL}]$ & $24.11 \pm 6.41$ & - \\
\hline
\end{tabular}

\section{Proliferation rates of lymphocytes isolated from patients with or without relapse of hyperthyroidism before and after treatment with methimazole}

The results obtained varied, with some patients having relapses of hyperthyroidism during the 36-month observation period, and some having no relapse. Significantly higher proliferation rates of Treg cells(Figure 2A) and of PMA-stimulated Treg cells (Figure 2B) before MMI treatment, as well as after the treatment, were observed in patients who had no relapse, in comparison with those who had a relapse of hyperthyroidism ( $p<0.0001$ and $p<0.05$, respectively) (Figure 2). A similar tendency, not statistically significant, was observed in cocultures of CD3 + cells and Treg cells maintained in the ratio 1:2 stimulated with PMA, and of CD3 + cells and Treg cells cultured in the ratio 1:1 stimulated with PMA. On the contrary, both CD3+ cells and the combination of CD3+ cells and Treg cells cultured in the ratio 2:1 and stimulated with PMA showed a tendency towards lower proliferation rates prior to MMI treatment and following treatment in patients who had no relapse, in comparison to those who had a relapse of hyperthyroidism (Table 2).

\section{Relationships between lymphocyte proliferation rates and selected clinical parameters of the examined patients}

Some relationships between lymphocyte proliferation rates and selected clinical parameters of the patients were observed (Table 3 ). A positive correlation between the proliferation rate of $\mathrm{CD} 3+$ lymphocytes prior to MMI treatment and fT3, as well as with fT4 concentration in peripheral blood at the time of the diagnosis, was found $(\mathrm{r}=0.839, \mathrm{p}<0.0001$ and $\mathrm{r}=0.375, \mathrm{p}<0.01$, respectively). The proliferation rates of $\mathrm{CD} 3+$ lymphocytes before and after treatment with MMI were positively correlated with the TSI index $(\mathrm{r}=0.968, \mathrm{p}<0.0001$ and $\mathrm{r}=0.522$, $\mathrm{p}<0.0001$, respectively). There was also a positive correlation between the proliferation rate of $\mathrm{CD} 3+\mathrm{lym}$ phocytes stimulated with PMA before the MMI treatment and $\mathrm{fT} 4$ concentration at the time of the diagnosis $(\mathrm{r}=0.967, \mathrm{p}<0.0001)$. We found also a positive correlation between the proliferation rate of $\mathrm{CD} 3+$ lymphocytes stimulated with PMA after MMI treatment and fT 3 concentration at the time of the diagnosis $(r=0.648, p<0.0001)$, as well as the TSI index $(\mathrm{r}=0.619, \mathrm{p}<0.0001)$. The volume of the thyroid gland was positively correlated with the proliferation rates of cocultures of CD3 + cells and Treg lymphocytes maintained in the ratio 1:1 and stimulated with PMA, both before and after MMI treatment $(\mathrm{r}=0.991$, $\mathrm{p}<0.0001$ and $\mathrm{r}=0.749, \mathrm{p}<0.0001$, respectively).

\section{Discussion}

Previous studies of Graves' disease showed a decreased number of Treg cells in the peripheral blood of GD patients [23, 24]. Moreover, Treg cell function appeared to be impaired in patients with GD. It has also
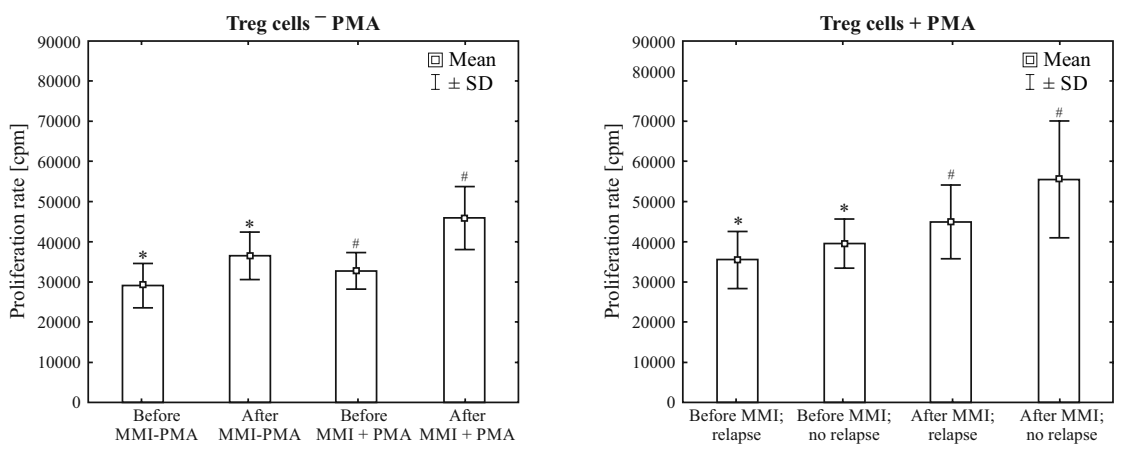

Figure 2. Proliferation rates of Treg cells unstimulated (- PMA) or stimulated with PMA (+ PMA) before and after MMI treatment, isolated from peripheral blood of patients with or without relapse of hyperthyroidism. A. Proliferation rates of unstimulated Treg cells before and after MMI treatment $\left({ }^{*} \mathrm{p}<0.0001 ;{ }^{*} \mathrm{p}<0.0001\right)$. B. Proliferation rates of Treg cells stimulated with PMA before and after MMI treatment $\left({ }^{*} \mathrm{p}<0.05 ;{ }^{*} \mathrm{p}<0.05\right)$ 
Table 2. Proliferation rates of CD3+ and Treg cells unstimulated (- PMA) or stimulated with PMA (+ PMA) before $(-\mathrm{MMI})$ and after $(+\mathrm{MMI})$ treatment with methimazole, isolated from patients with or without relapse of hyperthyroidism

\begin{tabular}{|c|c|c|c|c|}
\hline \multicolumn{2}{|c|}{ Experimental conditions for evaluating lymphocyte proliferation } & \multirow{2}{*}{$\begin{array}{c}\text { Relapse yes } \mathbf{n}=\mathbf{1 8} \\
48485 \pm 19673 \\
33021 \pm 13469\end{array}$} & \multirow{2}{*}{$\begin{array}{c}\text { Relapse no n = 32 } \\
43069 \pm 11343 \\
30684 \pm 11517\end{array}$} & \multirow{2}{*}{$\begin{array}{r}\text { P value } \\
>0.05 \\
>0.05\end{array}$} \\
\hline $\begin{array}{l}\text { CD3+ cells } \\
\text { - PMA }\end{array}$ & $\begin{array}{l}\text { - MMI } \\
+ \text { MMI }\end{array}$ & & & \\
\hline $\begin{array}{l}\text { CD3+ cells } \\
+ \text { PMA }\end{array}$ & $\begin{array}{l}\text { - MMI } \\
\text { + MMI }\end{array}$ & $\begin{array}{l}50074 \pm 11608 \\
38515 \pm 18222\end{array}$ & $\begin{array}{l}51269 \pm 10911 \\
34659 \pm 12075\end{array}$ & $\begin{array}{l}>0.05 \\
>0.05\end{array}$ \\
\hline $\begin{array}{l}\text { Treg cells } \\
\text { - PMA }\end{array}$ & $\begin{array}{l}-\mathrm{MMI} \\
+\mathrm{MMI}\end{array}$ & $\begin{array}{l}29113 \pm 5442 \\
32748 \pm 4592\end{array}$ & $\begin{array}{l}36486 \pm 5981 \\
45849 \pm 7887\end{array}$ & $\begin{array}{l}<0.0001 \\
<0.0001\end{array}$ \\
\hline $\begin{array}{l}\text { Treg cells } \\
+ \text { PMA }\end{array}$ & $\begin{array}{l}\text { - MMI } \\
+ \text { MMI }\end{array}$ & $\begin{array}{l}35528 \pm 7024 \\
44942 \pm 9172\end{array}$ & $\begin{array}{c}39476 \pm 6086 \\
55564 \pm 14570\end{array}$ & $\begin{array}{l}<0.05 \\
<0.05\end{array}$ \\
\hline $\begin{array}{l}\text { CD3+: Treg cells ratio } 1: 2 \\
\text { + PMA }\end{array}$ & $\begin{array}{l}-\mathrm{MMI} \\
+\mathrm{MMI}\end{array}$ & $\begin{array}{l}28592 \pm 7418 \\
34353 \pm 8672\end{array}$ & $\begin{array}{l}31630 \pm 10894 \\
37061 \pm 11096\end{array}$ & $\begin{array}{l}>0.05 \\
>0.05\end{array}$ \\
\hline $\begin{array}{l}\text { CD3+: Treg cells ratio 1:1 } \\
\text { + PMA }\end{array}$ & $\begin{array}{l}-\mathrm{MMI} \\
+\mathrm{MMI}\end{array}$ & $\begin{array}{l}43356 \pm 5811 \\
34986 \pm 6271\end{array}$ & $\begin{array}{c}45223 \pm 8619 \\
37385 \pm 10855\end{array}$ & $\begin{array}{l}>0.05 \\
>0.05\end{array}$ \\
\hline $\begin{array}{l}\text { CD3+: Treg cells ratio 2:1 } \\
\text { + PMA }\end{array}$ & $\begin{array}{l}-\mathrm{MMI} \\
+\mathrm{MMI}\end{array}$ & $\begin{array}{l}44684 \pm 9565 \\
35983 \pm 7468\end{array}$ & $\begin{array}{c}43958 \pm 10257 \\
34013 \pm 8350\end{array}$ & $\begin{array}{l}>0.05 \\
>0.05\end{array}$ \\
\hline
\end{tabular}

Data are presented as means $\pm \mathrm{SD}[\mathrm{cpm}]$

Table 3. Relationships between the proliferation rates of lymphocytes and selected clinical parameters of the examined patients

\begin{tabular}{|l|c|c|c|}
\hline Correlated parameters & Type of correlation (positive/negative) & R value & P value \\
\hline $\begin{array}{l}\text { Proliferation rate of CD3+ cells before MMI treatment and fT3 } \\
\text { concentration at the time of diagnosis }\end{array}$ & Positive & 0.839 & $<0.0001$ \\
\hline $\begin{array}{l}\text { Proliferation rate of CD3+ cells before MMI treatment and fT4 } \\
\text { concentration at the time of diagnosis }\end{array}$ & Positive & 0.375 & $<0.01$ \\
\hline $\begin{array}{l}\text { Proliferation rate of CD3+ cells before MMI treatment and } \\
\text { TSI index at the time of diagnosis }\end{array}$ & Positive & 0.968 & $<0.0001$ \\
\hline $\begin{array}{l}\text { Proliferation rate of CD3+ cells after MMI treatment and TSI } \\
\text { index at the time of diagnosis }\end{array}$ & Positive & 0.522 & $<0.0001$ \\
\hline $\begin{array}{l}\text { Proliferation rate of CD3+ cells stimulated with PMA before } \\
\text { MMI treatment and fT4 concentration at the time of diagnosis }\end{array}$ & Positive & 0.967 & $<0.0001$ \\
\hline $\begin{array}{l}\text { Proliferation rate of CD3+ cells stimulated with PMA after } \\
\text { MMI treatment and fT3 concentration at the time of diagnosis }\end{array}$ & Positive & 0.648 & $<0.0001$ \\
\hline $\begin{array}{l}\text { Proliferation rate of CD3+ cells stimulated with PMA after } \\
\text { MMI treatment and TSI index }\end{array}$ & Positive & 0.619 & $<0.0001$ \\
\hline $\begin{array}{l}\text { Proliferation rate of CD3+: Treg cells (1:1 ratio, +PMA) } \\
\text { before MMI treatment and the volume of the thyroid gland }\end{array}$ & Positive & 0.991 & $<0.0001$ \\
\hline $\begin{array}{l}\text { Proliferation rate of CD3+: Treg cells (1:1 ratio, +PMA) } \\
\text { after MMI treatment and the volume of the thyroid gland }\end{array}$ & & 0.749 & $<0.0001$ \\
\hline
\end{tabular}

been suggested that decreased Treg cell activity may be a crucial factor in the pathogenesis of GD, and that an increase in the number of Treg cells (or an improvement in their function) might help in the remission of this disease [4]. Hu et al. showed that coculture of Treg cells and CD4+CD25-T cells (mixed at a 1:10 ratio) with dexamethazone (DEX) for $72 \mathrm{~h}$ improved the suppressive function of Treg cells in patients with GD. The activity of CD4+CD25+Treg cells was evaluated by the proliferation rate of $\mathrm{CD} 4+\mathrm{CD} 25-\mathrm{T}$ cells with flow cytometry. Dexamethazone is a glucocorticoid usually employed as an immunosuppressive agent in the treatment of Graves' ophthalmopathy. In the studies of $\mathrm{Hu}$ et al., dexamethazone appeared to affect the activity of Treg cells [4]. The immunosuppressive properties of DEX were also used to improve the effects of methimazole treatment by Mao et al. [25]. Their new strategy for dealing with GD involved 
treatment with methimazole (18 months) combined with an intrathyroid injection of DEX (3 months). These authors observed markedly reduced relapse rates of hyperthyroidism compared to treatment with methimazole alone $(7.4 \%$ vs. $51 \%$ ) during the 2 -year follow-up period. The thyroid volume also decreased [25]. However, the mechanism through which dexamethasone reduced the relapse rate of GD was not fully understood [4].

The immunomodulatory function of Treg cells and their influence on the proliferative potential of other T lymphocytes were studied by Glick et al. [3]. They assessed Treg activity in various autoimmune thyroid diseases, including Graves' disease, through the inhibition of the proliferation of blood-derived $\mathrm{T}$ effector cells by Tregs in a coculture with the use of radioactive thymidine incorporation assay. The authors compared various methods of cell stimulation, and found that Tregs of patients with autoimmune thyroid diseases were less capable of inhibiting the proliferation of $\mathrm{T}$ cells as compared to healthy controls. However, the impairment was dependent on the type of stimulation. In line with our findings, Tregs appeared to be partly dysfunctional in these patients [3].

Our study demonstrated that Treg cells isolated from the peripheral blood of children suffering from Graves' disease show lower proliferative potential than CD3 + T lymphocytes (assessed in vitro by thymidine incorporation assay, similarly to Glick et al. study [3]). Methimazole (MMI) treatment reduced the proliferative activity of CD3 $+\mathrm{T}$ cells and increased the proliferation rates of Treg cells. Moreover, in a model of cocultured Tregs and CD3 $+\mathrm{T}$ cells we demonstrated that Tregs were not capable of efficiently inhibiting the proliferation of $\mathrm{CD} 3+\mathrm{T}$ cells in GD patients and that methimazole reduced the proliferative activity of $\mathrm{T}$ lymphocytes in cocultures with Treg cells. These results suggest that Tregs were partly dysfunctional in Graves' disease and seemed to be suppressed by CD3 $+\mathrm{T}$ cells, and that MMI possesses some immunomodulatory effects. Our observations are similar to the results described by $\mathrm{Hu}$ et al. concerning the role of dexamethasone in immunosuppression of autoimmune thyroid diseases [4]. Moreover, some earlier in vitro studies suggested the immunomodulatory effect of methimazole on lymphocyte populations, although the results were sometimes contradictory. Bagnasco et al. [26] did not notice any effect of MMI on in vitro proliferation of $\mathrm{T}$ cells, whatever the activation pathway considered (stimulation with phytohemagglutinin, PHA, or anti -CD3 or anti-CD2 monoclonal antibodies). Weetman observed an immunomodulatory effect of MMI on peripheral blood mononuclear cells isolated from normal subjects and subsequently stimulated in vitro with mitogens (PHA, concanavalin A, i.e. Con A or pokeweed mitogen) in the presence of $10-100 \mathrm{mmol} / \mathrm{L}$ methimazole. There was an increase in IL-2 activity in the culture supernatants. This effect was apparent between 24 and $60 \mathrm{~h}$ and enhanced the proliferation of T cells in methimazole-supplemented cultures [27]. Sharma et al. demonstrated that mitogen-stimulated lymphocytes showed increased proliferation rate in the presence of MMI at a concentration of $114.2 \mu \mathrm{g} /$ $/ \mathrm{mL}$ [28]. Okabe et al. used peripheral blood lymphocytes from healthy individuals to study the effects of antithyroid drugs on Con A-induced suppressor activity of these cells against mitogen-induced proliferation of responder cells. They found an increase in Con A-stimulated suppressor function of MMI in all these subjects, and suggested that the enhancement in the suppressor activity of peripheral blood lymphocytes by antithyroid drugs may contribute, in part, to the remission of Graves' disease [29]. However, most of these studies were conducted on lymphocytes isolated from the peripheral blood of healthy donors and stimulated in vitro with different mitogens in the presence of MMI. These results also corresponded to observations made by Liu et al. on mouse splenic lymphocytes. They observed that the proliferative response of mouse splenocytes to Con A was reduced when the mice were treated with $0.1 \%$ MMI [30].

Subsequent studies carried out by Ben-Skowronek et al. [31] analyzed subsets of lymphocytes isolated from the peripheral blood of children with the early phase of Graves' disease and of lymphocytes from the thyroid tissue of children with the late phase of GD. They noticed a negative correlation between the duration of therapy with methimazole and the amount of CD3 + T cells in the thyroid interstitium. However, no correlation was found between lymphocyte subpopulations and thyroid hormones' serum levels prior to MMI treatment [31].

Our study, conducted on lymphocytes isolated from the peripheral blood of children suffering from Graves' disease, revealed some positive correlations between the $\mathrm{T}$ cell proliferation rates prior to MMI treatment and fT3, as well as with fT4 concentration in peripheral blood at the time of the diagnosis. CD3+ lymphocyte proliferation rates before and after MMI treatment were also positively correlated with the TSI index. Enlargement of the thyroid gland is often observed in GD and depends on the duration of the disease [32]. In our study, the volume of the thyroid gland positively correlated with the proliferation rate of CD3 + cells and Treg lymphocytes cultured in ratio of 1:1 and stimulated with PMA both before and after MMI treatment. Our results therefore in- 
dicate a strong link between GD severity and T cell proliferation.

We also observed significantly higher proliferation rates for Treg cells and Tregs stimulated with PMA both prior to and following MMI treatment in patients who had no relapse, than in the case of those who suffered a relapse of hyperthyroidism. These results indicate the key role of Tregs in the control of the course of GD. The significant role of Treg cells in the remission of Graves' disease was also noticed by $\mathrm{Hu}$ et al. in their studies with dexamethazone [4].

In summary, we have shown that Treg cells isolated from the peripheral blood of children suffering from Graves' disease have lower proliferative potential than CD3 + T lymphocytes. Moreover, coculturing Tregs and CD3 + cells showed that Tregs were not capable of efficiently inhibiting the proliferation of CD3+ lymphocytes. Only a significant excess of Tregs cocultured with $\mathrm{CD} 3+$ cells led to a decrease in the proliferation rate of $\mathrm{CD} 3+\mathrm{T}$ cells. These observations are in line with recent studies indicating that the more important factor contributing to autoimmunity is not the absolute number of Treg cells, but rather the ratio of Treg to T effector cells. Antithyroid drugs, such as methimazole, are used as a first-line treatment in children and adolescents with Graves' disease to normalize the concentration of thyroid hormones circulating in the blood [20,33]. We found that methimazole can reveal some immunomodulatory effects on both Treg cells and CD3 + T lymphocytes. Our results suggest that Treg cells seem to be suppressed by $\mathrm{CD} 3+\mathrm{T}$ cells, and that methimazole can restore the partly dysfunctional suppressive function of Treg lymphocytes in Graves' disease.

\section{Acknowledgements}

This work was supported by research grant no. $\mathrm{N} \mathrm{N}$ 402359338 from the Polish State Funds for Scientific Research.

\section{References}

1. Vanderpump MP. The epidemiology of thyroid disease. $\mathrm{Br}$ Med Bull. 2011;99:39-51.

2. Nielsen J, Jensen RB, Juul A. Increased sex hormone-binding globulin levels in children and adolescents with thyrotoxicosis. Horm Res Paediatr. 2013;79:157-161.

3. Glick AB, Wodzinski A, Fu P, Levine AD, Wald DN. Impairment of regulatory $\mathrm{T}$ cell function in autoimmune thyroid disease. Thyroid. 2013;23:871-878.

4. Hu Y, Tian W, Zhang L-L et al. Function of regulatory T-cells improved by dexamethasone in Graves' disease. Eur J Endocrinol. 2012;166:641-646.

5. Povoleri GAM, Scottà C, Nova-Lamperti EA, John S, Lombardi G, Afzali B. Thymic versus induced regulatory T cells — who regulates the regulators? Front Immunol. 2013;4:169.
6. Kahaly GJ, Shimony O, Gellman YN et al. Regulatory T-Cells in Graves' orbitopathy: Baseline findings and immunomodulation by anti-t lymphocyte globulin. J Clin Endocrinol Metab. 2011;96:422-429.

7. Güven A, Ecevit A, Sözer O, Tarcan A, Tarcan A, Ozbek N. Correlation between the cord vitamin D levels and regulatory T cells in newborn infants. Eur J Pediatr. 2012;171:1161-1166.

8. Heninger AK, Theil A, Wilhelm C et al. IL-7 abrogates suppressive activity of human $\mathrm{CD} 4+\mathrm{CD} 25+\mathrm{FOXP} 3+$ regulatory $\mathrm{T}$ cells and allows expansion of alloreactive and autoreactive T cells. J Immunol. 2012;189:5649-5658.

9. Monti P, Heninger AK, Bonifacio E. Differentiation, expansion, and homeostasis of autoreactive T cells in type 1 diabetes mellitus. Curr Diab Rep. 2009;9:113-118.

10. Nelson BH. IL-2, regulatory T cells, and tolerance.J Immunol. 2004;172:3983-3988.

11. Schwartz RH. Natural regulatory T cells and self-tolerance. Nat Immunol. 2005;6:327-330.

12. 12. Saitoh O, Nagayama Y. Regulation of Graves' hyperthyroidism with naturally occurring $\mathrm{CD} 4 \mathrm{CCD} 25 \mathrm{C}$ regulatory $\mathrm{T}$ cells in a mouse model. Endocrinology 2006;147: 2417-2422.

13. Crescioli C, Cosmi L, Borgogni E et al. Methimazole inhibits CXC chemokine ligand 10 secretion in human thyrocytes. J Endocrinol. 2007;195:145-155.

14. Liblau RS, Singer SM, McDevitt HO. Th1 and Th2 CD4+ $\mathrm{T}$ cells in the pathogenesis of organ-specific autoimmune diseases. Immunol Today. 1995;16:34-38.

15. Mills KH. Regulatory T cells: friend or foe in immunity to infection? Nat Rev Immunol. 2004;4:841-855.

16. Stassi G, Di Liberto D, Todaro M et al. Control of target cell survival in thyroid autoimmunity by $\mathrm{T}$ helper cytokines via regulation of apoptotic proteins. Nat Immunol. 2000;1:483-488.

17. Abbas AK, Murphy KM, Sher A. Functional diversity of helper T lymphocytes. Nature. 1996;383:787-793.

18. Datta S, Sarvetnick N. Lymphocyte proliferation in immune-mediated diseases. Trends Immunol. 2009;30:430-438.

19. Hori S, Nomura T, Sakaguchi S. Control of regulatory T cell development by the transcription factor Foxp3. Science. 2003;299:1057-1061.

20. Sato H, Sasaki N, Minamitani K et al. Higher dose of methimazole causes frequent adverse effects in the management of Graves' disease in children and adolescents. $J$ Pediatr Endocrinol Metab. 2012;25:863-867.

21. Antonelli A, Rotondi M, Fallahi P et al. Increase of interferon-gamma-inducible CXC chemokine CXCL10 serum levels in patients with active Graves' disease, and modulation by methimazole therapy. Clin Endocrinol. 2006;64:189-195.

22. Molnar I. The balance shift in Th1/Th2 related IL-12/IL-5 cytokines in Graves' disease during methimazole therapy. Autoimmunity. 2007;40:31-37.

23. Deshun P, Shin YH, Gopalakrishnan G, Hennessey J, De Groot L. Regulatory T-cells in Graves-Disease. Clin Enocrinol. 2009;71:587-593.

25. Bossowski A, Moniuszko M, Dąbrowska M et al. Lower proportions of $\mathrm{CD} 4+\mathrm{CD} 25$ (high) and $\mathrm{CD} 4+\mathrm{FoxP} 3$, but not CD4+CD25+CD127(low) FoxP3 + T cell levels in children with autoimmune thyroid diseases. Autoimmunity. 2013;46:222-230.

26. Mao XM, Li HQ, Li Q et al. Prevention of relapse of Graves' disease by treatment with an intrathyroid injection of dexamethasone. J Clin Endocrinol Metab. 2009;94:4984-4991.

27. Bagnasco M, Venuti D, Ciprandi G, Pesce G, Paolieri F, Canonica GW. The effect of methimazole on the immune system is unlikely to operate directly on T lymphocytes. J Endocrinol Invest. 1990;13:493-499. 
28. Weetman AP. Effect of the anti-thyroid drug methimazole on interleukin-1 and interleukin-2 levels in vitro. Clin Endocrinol (Oxf). 1986;25:133-142.

29. Sharma BS, Elias AN. Effects of methimazole on human lymphocyte proliferation and natural killer cell activity. Gen Pharmacol. 1987;18:449-453.

30. Okabe N, Mori R, Miake S, Inoue K. Effects of antithyroid drugs on Con A-induced suppressor cell activity. J Clin Lab Immunol. 1984;13:167-169.
31. Liu W-K, Mak N-K, Wong C-C. Immunomodulatory effect of methimazole on inbred mice. Immunobiology 1989;180:23-32.

32. Ben-Skowronek I, Sierocinska-Sawa J, Korobowicz E, Szewczyk L. Lymphocytes in peripheral blood and thyroid tissue in children with Graves' disease. World J Pediat. 2008;4:274-282.

33. Brent GA. Clinical Practise. Graves' disease. N Engl J Med. 2008;358:2594-2605.

34. Cooper DS. Antithyroid drugs. $N$ Engl J Med. 2005;352: 905-917.

Submitted: 19 February, 2014 Accepted after reviews: 8 April, 2014 